\title{
Cochlear Fistula in Chronic Otitis Media without Cholesteatoma
}

\author{
Changyun Kwon, Jeong Hwan Choi, and Hoon Young Woo \\ Department of Otorhinolaryngology-Head and Neck Surgery, Inje University College of Medicine, Sanggye Paik Hospital, Seoul, Korea
}

$\begin{array}{ll}\text { Received } & \text { April 11, 2017 } \\ \text { Revised } & \text { June 9,2017 }\end{array}$

Accepted June 13, 2017

Address for correspondence Jeong Hwan Choi, MD

Department of Otorhinolaryngology-

Head and Neck Surgery,

Inje University College of Medicine,

Sanggye Paik Hospital,

1342 Dongil-ro, Nowon-gu,

Seoul 01757, Korea

Tel $+82-2-950-1104$

Fax +82-2-935-6220

E-mail choijh92@paik.ac.kr
Cochlear fistula in the chronic otitis media (COM) without cholesteatoma is an extremely rare with only a few cases reported in the literature to this date. We describe a case of cochlear fistula observed in a female with COM without cholesteatoma. This report presents the first clinical case of a transtympanic iatrogenic trauma by habitual cotton swabs probably causing cochlear fistula.

J Audiol Otol 2017;21(2):112-114

KEY WORDS: Cochlear fistula $\cdot$ Otitis media $\cdot$ Cholesteatoma

\section{Introduction}

Cochlear fistula in the chronic otitis media (COM) without cholesteatoma is an extremely rare with only a few cases reported in the literature to this date [1-3]. We describe a case of cochlear fistula observed in a female patient with COM without cholesteatoma. This report presents the first clinical case of a transtympanic iatrogenic trauma by habitual cotton swabs probably causing cochlear fistula. Approval for this report was obtained from Inje University Sanggye Paik Hospital Institutional Review Board (IRB No. SGPIAK 2016-11-011).

\section{Case Report}

A 69-year-old woman presented at our hospital with 20year history of right-side hearing impairment, otorrhea, ear fullness and tinnitus without vertigo. She habitually used cotton swabs for cleaning her ear due to frequent episodes of otorrhea and she also reported that she put cotton swaps deeply for some relief of ear fullness. She had a medical history of hypertension and diabetes mellitus. On physical examination,

This is an Open Access article distributed under the terms of the Creative Commons Attribution Non-Commercial License (http://creativecommons.org/licenses/by-nc/4.0/) which permits unrestricted non-commercial use, distribution, and reproduction in any medium, provided the original work is properly cited. a perforation of the tympanic membrane with granulation tissue was observed. The mucosa of the tympanic cavity especially above the promontory was very thick (Fig. 1). A puretone audiogram (PTA) showed right mixed type hearing loss with 55 decibels $(\mathrm{dB})$ of bone conduction $(\mathrm{BC})$ threshold and $90 \mathrm{~dB}$ of air conduction (AC) threshold. In comparison, the PTA in the left side was $36 \mathrm{~dB}$ of $\mathrm{BC}$ threshold and $46 \mathrm{~dB}$ of $\mathrm{AC}$ threshold (Fig. 2). Bacterial examination of the otorrhea subsequently yielded methicillin-resistant Staphylococcus epidermidis. High-resolution computed tomography (CT) was compatible with COM without cholesteatoma.

The patient went through surgery for COM via a postauricular approach. A canal-wall-up tympanomastoidectomy was performed. During the operation, a hard thickened mucosa was observed at the cochlear promontory. In removing the thickened tissue around promontory, above which fluctuation of the mucosa was noticed. An unconfirmed diagnosis of cochlear fistula was made and then CT was reviewed thoroughly. It showed bony defect of the first turn of the cochlea (Fig. 3). During the operation, the intact endosteum of the cochlea was noticed. Temporalis fascia was placed over the dehiscent cochlea. We did not find any other cholesteatoma lesions in the middle ear cavity. She did not complain of dizziness and further hearing loss after surgery. 


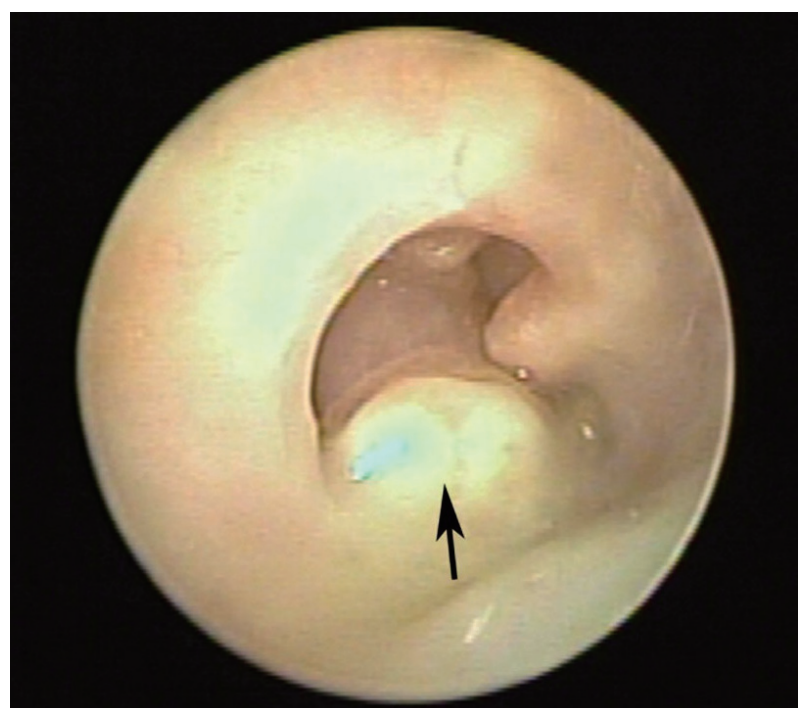

Fig. 1. Otoendoscopic view, right ear. The perforation of the tympanic membrane with granulation tissue and very thickened remnant of tympanic membrane and mucosa of the tympanic cavity especially above the promontory (arrow) with serous discharge were observed.

\section{Discussion}

Cochlear fistula in the COM without cholesteatoma is an extremely rare with only a few cases reported in the literature to this date [1-3]. The promontory is not usual site of bone destruction. It is very dense and not the common site of keratin accumulation and pressure necrosis even in COM with cholesteatoma unlike lateral semicircular canal.

In the COM with cholesteatoma, various mechanisms of bone erosion have been suggested. Besides pressure ischemia [4], other factors such as $\mathrm{pH}$ alterations, the activity of osteoclasts, production of osteolytic enzymes by the matrix of cholesteatoma, or a combination of the above been considered to play a role in bone resorption [5-7].

In this case of COM without cholesteatoma, repeated mechanical irritation such as habitual cotton swabs may cause chronic mucosal trauma and continuous inflammation in the cochlear promontary. Furthermore, inflammatory mediators induced bony remodeling in cochlear promontory. As a result,

Fig. 2. A PTA showed (A) mixed type hearing loss with $55 \mathrm{~dB}$ of $\mathrm{BC}$ threshold and $90 \mathrm{~dB}$ of $\mathrm{AC}$ threshold. In comparison, the PTA in the (B) was $36 \mathrm{~dB}$ of $\mathrm{BC}$ threshold and $46 \mathrm{~dB}$ of AC threshold. PTA: pure-tone audiogram, $\mathrm{BC}$ : bone conduction, $\mathrm{AC}$ : air conduction, $\mathrm{dB}$ : decibels.
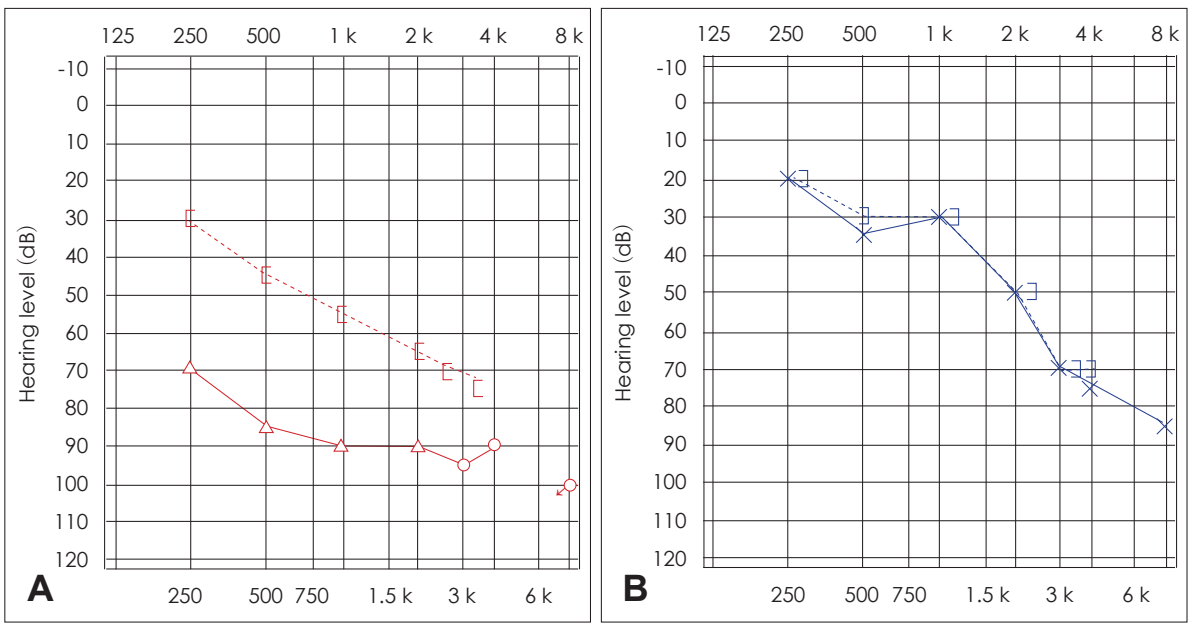

Fig. 3. High-resolution axial $(\mathrm{A})$ and coronal CT (B) scans of right temporal bone. CT scans shows severe mucosal swelling (arrows) above the destroyed bone covering the basal turn of cochlea (arrowheads).
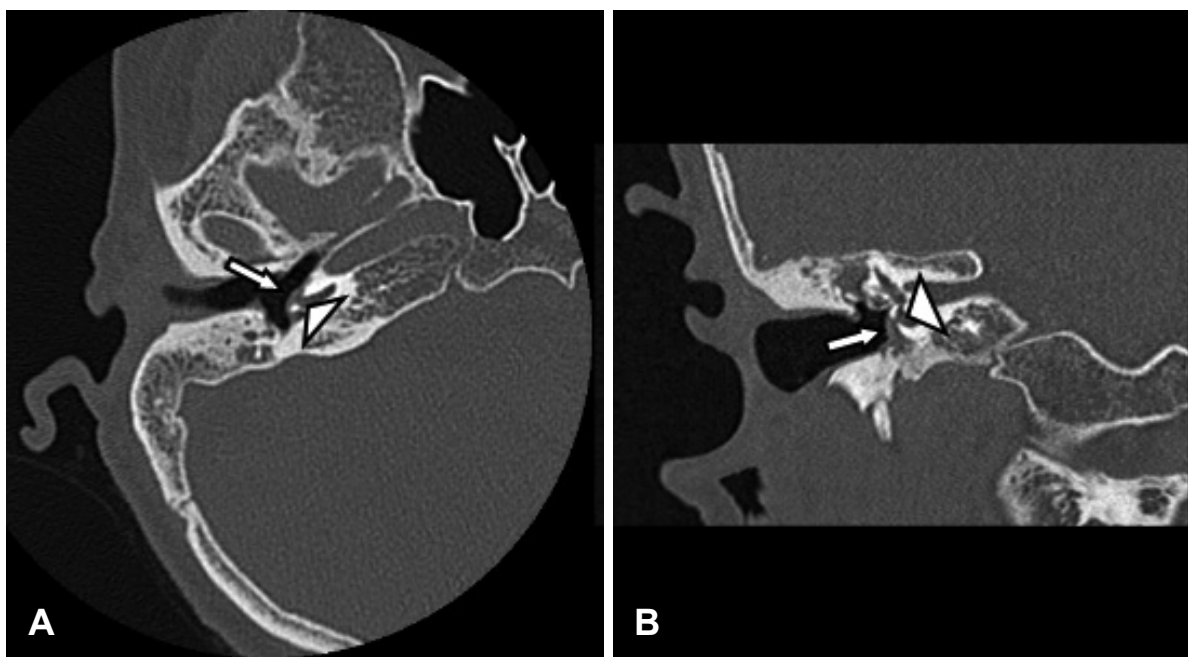
those processes might lead to the cochlear fistula.

Sensorineural hearing loss in COM can be related to either mechanical or chemical iirritaions. Mechanical damage may include continuous trauma to the membranous labyrinth, leading to fistula formation between the endolymph and perilymph, causing a loss of hearing [8,9]. Chemical damage can be caused by the penetration of noxious substances such as bacterial toxins into the labyrinth. Endogenous toxins that may be present in middle ear effusions (lipopolysaccharides, prostaglandins, and leukotrienes) are also possible mediators of sensorineural hearing loss [10-13].

However, our patient's BC was relatively preserved. There are several hypotheses regarding the mechanism of hearing preservation. Natural segmentation of the labyrinth, a kind of anatomic adaptation, might prevent loss of endolymph [14].

When the cochlear endosteum was invaded by the cholesteatoma or was damaged during surgery, severe hearing loss occurred [14].

In the reported cases, the membranous labyrinth was left intact with preserved BC [15], even though membranous labyrinth conservation is not always synonymous with hearing preservation.

Chronic irritations by mechanical stimulation and inflammatory mediators may also cause local changes around the fistula such as thickening the endosteum of the cochlea and protecting involvement of membranous labyrinth. But further irritation at the endosteum could cause the hearing loss. A thick mucosal layer covered the unexpected small bone dehiscence of the promontory and, fortunately, its removal did not cause a lesion of the endosteum, allowing preservation of BC.

However, further evaluation is needed to find exact pathologic mechanism among mechanical irritation, cochlear fistula and hearing preservation.

In conclusion, cochlear fistula can also be observed in COM without cholesteatoma. It cannot be emphasized enough that CT should be read thoroughly preoperatively even in the COM without cholesteatoma case. The presence of a fistula is not always associated with severe hearing loss, so every effort should be made to not damage the membranous labyrinth. Inflammatory tissue or cholesteatoma matrix can be removed from the fistulous tract without injuring the membranous labyrinth. If any doubt of damaging the membranous labyrinth exists, the matrix must be exteriorized and long-term follow-up is strongly recommended.

Therefore, even in COM without cholesteatoma, tympanoplasty would be recommended for preventing cochlear damage.

\section{Acknowledgments}

This work was supported by Grant form Inje University, 2009.

\section{Conflicts of interest}

The authors have no financial conflicts of interest.

\section{REFERENCES}

1) de Zinis LO, Campovecchi C, Gadola E. Fistula of the cochlear labyrinth in noncholesteatomatous chronic otitis media. Otol Neurotol 2005;26:830-3.

2) Hahn Y, Bojrab DI. Cochlear fistula in a noncholesteatomatous ear. Ear Nose Throat J 2014;93:E9-10.

3) Sakaida H, Takeuchi K. Cochlear fistula as a late consequence of tympanomastoidectomy. Otol Neurotol 2015;36:e148-9.

4) Abramson M, Harker LA, McCabe BF. Labyrinithine fistula complicating chronic suppurative otitis media. Arch Otolaryngol 1974; 100:141-2.

5) Hansen T, Unger RE, Gaumann A, Hundorf I, Maurer J, Kirkpatrick $\mathrm{CJ}$, et al. Expression of matrix-degrading cysteine proteinase cathepsin K in cholesteatoma. Mod Pathol 2001;14:1226-31.

6) Uno Y, Saito R. Bone resorption in human cholesteatoma: morphological study with scanning electron microscopy. Ann Otol Rhinol Laryngol 1995;104:463-8.

7) Hamzei M, Ventriglia G, Hagnia M, Antonopolous A, Bernal-Sprekelsen M, Dazert S, et al. Osteoclast stimulating and differentiating factors in human cholesteatoma. Laryngoscope 2003;113:436-42.

8) Ars B, Claes J, Casselman J, Ars-Piret N. Preservation of cochlear function after extensive labyrinthine destruction. Am J Otol 1996; 17:40-5.

9) Eisenman DJ, Parisier SC. Is chronic otitis media with cholesteatoma associated with neurosensory hearing loss? Am J Otol 1998;19: 20-5.

10) Stenqvist M, Anniko M, Pettersson A. Effect of Pseudomonas aeruginosa exotoxin A on inner ear function. Acta Otolaryngol 1997;117: 73-9.

11) Engel F, Blatz R, Kellner J, Palmer M, Weller U, Bhadki S. Breakdown of the round window membrane permeability barrier evoked by streptolysin O: possible etiologic role in development of sensorineural hearing loss in acute otitis media. Infect Immun 1995;63:1305-10.

12) Guo Y, Wu Y, Chen W, Lin J. Endotoxic damage to the stria vascularis: the pathogenesis of sensorineural hearing loss secondary to otitis media? J Laryngol Otol 1994;108:310-3.

13) Papp Z, Rezes S, Jókay I, Sziklai I. Sensorineural hearing loss in chronic otitis media. Otol Neurotol 2003;24:141-4.

14) Phelps PD. Preservation of hearing in the labyrinth invaded by cholesteatoma. J Laryngol Otol 1969;83:1111-4.

15) Canalis RF, Abemayor E, McClean P. Preservation of hearing in cholesteatomas with inner ear invasion. J Otolaryngol 1989;18:374-9. 